\title{
A Study of Awareness about "Nutrition in Hypertension" among College Teachers in a Semi Urban Town of South India
}

\author{
M. R. Suchitra', S. Vadivel' ${ }^{2}$, M. Balasubramanian ${ }^{2}$ and S. Parthasarathy ${ }^{3}$ \\ 'SASTRA University (SRC), Kumbakonam, Thanjavur - 612001, Tamil Nadu, India \\ 2Department of Geography, Govt College for Men, (arts - autonomous), Kumbakonam, \\ Thanjavur - 612001, Tamil Nadu, India \\ ${ }^{3}$ Department of Anaesthesiology, Mahatma Gandhi Medical College and Research Institute, Puducherry, India
}

\begin{abstract}
Hypertension is reported to be the fourth contributor to premature death in developed countries and the seventh in developing countries. Recent reports indicate that nearly 1 billion adults (more than a quarter of the world's population) had hypertension in 2000 , and this is predicted to increase to 1.56 billion by 2025. The main aim of the study is to find out the level of knowledge of nutritional therapy in hypertension among college teachers through a structured questionnaire and to impart the necessary awareness about the same. This study was based on questionnaire survey by scientifically tested random sampling procedure. The necessary approval for the study was obtained from the academic committee of the Government Arts College for men (autonomous). As the study is a simple questionnaire one, there are no ethical issues. The information was collected from 911 teachers working in colleges and higher institutions. The collected data were entered and analyzed with the help of SPSS software. Statistical tests included simple frequency, percentage and Pearson Correlation techniques which were performed for the collected data. This present study demonstrates that the majority of the respondents were aged either between 31-40 and 41-50 years. 47.4 per cent and 36.6 per cent of male and female were having hypertension respectively which is higher than the general population. According to the 'Suchitra's grading' of nutrition awareness, the level of knowledge in hypertension, 24.1 percent of the respondents are grade I, 26.5 percent grade II, 22.9 percent grade III and 26.5 percent grade IV. Its clear that college teachers lack awareness about nutrition in hypertension. The teachers who suffer from the disease i.e. hypertension had better awareness.
\end{abstract}

Keywords: Awareness, Hypertension, Nutrition, Teachers

\section{Introduction}

As per the World Health Statistics 2012, of the estimated 57 million global deaths in 2008, 36 million (63\%) were due to Non Communicable Diseases (NCDs). The largest proportion of NCD deaths is caused by cardiovascular diseases $(48 \%)$. In terms of deaths, hypertension is one of the leading behavioural and physiological risk factor to which 13.0 per cent of global deaths are attributed.
Hypertension is reported to be the fourth contributor to premature death in developed countries and the seventh in developing countries. Recent reports indicate that nearly 1 billion adults (more than a quarter of the world's population) had hypertension in 2000, and this is predicted to increase to 1.56 billion by $2025 .{ }^{1}$ At this juncture, the college teachers form an essential element in transfer of vital information to the society. They can achieve this through student contact in their day to day work. Hence

*Author for correspondence 
an adequate level of knowledge among college teachers about any subject becomes important to strengthen the public awareness. Usually patients with hypertension take drugs for control of blood pressure. Nutritional therapy in hypertension is gaining importance nowadays. Hence we wished to conduct a study on the knowledge of teachers working in different colleges in a semi urban town of South India.

\section{Aims and Objectives}

The purpose of the study is to investigate the level of awareness among College Teachers on the role of Nutrition therapy in Hypertension. Thus, the present study was aimed to analyse the influencing factors like college teacher's age, he/she a patient of hypertension, awareness about nutrition, interest in learning and level of knowledge in hypertension.

\section{Methodology}

This study was based on a questionnaire survey by scientifically tested random sampling procedure. The information was collected from 911 teachers working in colleges and higher institutions. The collected data were entered and analyzed with the help of SPSS software. Only simple frequency, percentage and Pearson Correlation techniques were performed for findings and interpretations. Regarding the level of awareness, this present study also introduced a new grading scale which was named as 'Suchitra's grading' of nutrition knowledge in hypertension (Table 1).

Table 1. Showing Suchitra’s grading

Levels of knowledge
$\mathbf{0}$ - Nil
$\mathbf{1}$ - Avoidance of salt, performance of regular exercise
$\mathbf{2}$ - Weight reduction, stop alcoholism, avoid coffee
$\mathbf{3}$ - DASH diet (dietary approach to stop hypertension) -
decrease salt and increase intake of foods rich in potassium,
calcium and magnesium, low fat dairy products, nuts
(Banana, potato, mango, Green leafy vegetables, whole
grains)

As the above levels are devised after a decade of nutrition practice, this grading is not published anywhere. As there are no published data on such scales, we have to introduce such a new knowledge level scoring system which needs to be validated in future. The interest to know the details among teachers was also noted. All the teachers were later enlightened about the role of nutrition in hypertension. All their queries regarding the role of nutrition in hypertension were cleared. Only a simple question was asked to know whether they were hypertensives. No recording of blood pressure was made in any case. The age, qualification, work place, sex, sufferer of hypertension was correlated with the knowledge of nutrition on hypertension. All data were collected in a proforma which is shown below. This proforma was being introduced by us for the first time as there are no such trials earlier.

\section{Proforma \\ Age \\ Sex \\ Private / government \\ Department \\ Are you hypertensive? Yes/ no \\ Awareness about nutrition in hypertension - Yes / no \\ Interested in learning}

The above levels are devised after a decade of nutrition practice and not published anywhere. Hence, it may be called as Suchitra's grading of nutrition knowledge in hypertension

This study is a simple questionnaire study among college teachers to know their level of knowledge and impart them with necessary education if they were unaware. As such any hypothesis to prove or disprove does not exist. The aims were expressed, and the research was carried out to establish the data on such objectives.

\section{Results}

The information was collected through the questionnaire survey from male 392 (43.0\%) and female 519 (57.0\%) college teachers working in and around Kumbakonam town of South India and they were the respondents of this study. Their ages $<30.0$ (male $15.6 \%$ and female $26.0 \%$ ) was 21.5 per cent, 31 to 40 (male $48.7 \%$ and female $49.3 \%$ ) 49.0 percent, 41 to 50 (male $31.9 \%$ and female $21.0 \%$ ) 25.7 percent and 51 to 60 (male $3.8 \%$ and female $3.7 \%$ ) 3.8 percent. $52.6,49.7$ and $47.4,50.3$ percent of the male and female are working in private and government colleges respectively. 
This present study (Table 2) proved that 47.4 percent and 36.6 percent of male and females were hypertensive respectively. 62.5 percent of male and 63.8 percent of the female respondents revealed that they were aware of nutrition in hypertension. However, 77.6 percent of male and 81.3 per cent of female confirmed that they are interested in learning about hypertension. In contrast, the respondents who had hypertension, according to this 'Suchitra's grading', revealed that their levels of knowledge were (Grade-I - nil) for 24.1 percent (23.7\% male, $24.5 \%$ female) of the respondents. 26.5 percent of male and 26.4 percent of female respondents are (Grade-II) avoiding salt and performance of regular exercise. 22.9 per cent of the respondents (26.3 percent of male, 20.4 percent of female) are (Grade-III) conveyed that they did weight reduction, stop alcoholism and avoiding coffee. 23.5 percent of male and 28.7 percent of female respondents are (Grade-IV) following DASH diet (dietary approach to stop hypertension) - decrease salt and increase intake of foods rich in potassium, calcium and magnesium, low fat dairy products, nuts (banana, potato, mango, green leafy vegetables, whole grains).

\subsection{Correlates of Hypertension}

The Result expressed in Table 3 is illustrating the correlated variables of respondents. In general, the variable 'age' and 'occupation' are having positive relationship with the variable 'levels of knowledge' $(\mathrm{P}=0.122$, Sig. (2-tailed $=0.001) ; \mathrm{P}=0.076$, Sig. (2-tailed $=0.022)$. This clearly shows that the increasing age with decrease of levels of knowledge towards to hypertension at 1.0 percent and 5.0 percent significant level respectively.

Similarly, the variable 'Are you hypertensive?' and 'Awareness about nutrition in hypertension' are having positive association ( $\mathrm{P}=0.091)$, Sig. (2-tailed $=0.006)$; $\mathrm{P}=0.119$, Sig. (2-tailed $=0.001)$ with the variable 'Are you interested in learning?' This is undoubtedly proved that

Table 2. Variables present to identify attributes for male and female

\begin{tabular}{|c|c|c|c|c|c|c|c|c|}
\hline S1.No & Variables & Attributes & Male & $\%$ & Female & $\%$ & Total & $\%$ \\
\hline \multirow[t]{4}{*}{1} & \multirow[t]{4}{*}{ Age } & $<30$ & 61 & 15.6 & 135 & 26.0 & 196 & 21.5 \\
\hline & & $31-40$ & 191 & 48.7 & 256 & 49.3 & 447 & 49.0 \\
\hline & & $41-50$ & 125 & 31.9 & 109 & 21.0 & 234 & 25.7 \\
\hline & & $51-60$ & 15 & 3.8 & 19 & 3.7 & 34 & 3.8 \\
\hline \multirow[t]{2}{*}{2} & \multirow[t]{2}{*}{ Sex } & Male & 392 & 43.0 & - & - & 392 & 43.0 \\
\hline & & Female & 519 & 57.0 & - & - & 519 & 57.0 \\
\hline \multirow[t]{2}{*}{2} & \multirow[t]{2}{*}{ Occupation } & Private & 206 & 52.6 & 258 & 49.7 & 464 & 50.9 \\
\hline & & Government & 186 & 47.4 & 261 & 50.3 & 447 & 49.1 \\
\hline \multirow[t]{2}{*}{3} & \multirow[t]{2}{*}{ Are you hypertensive? } & Yes & 186 & 47.4 & 190 & 36.6 & 376 & 41.3 \\
\hline & & No & 206 & 52.6 & 329 & 63.4 & 535 & 58.7 \\
\hline \multirow[t]{2}{*}{4} & \multirow[t]{2}{*}{ Awareness about nutrition in hypertension } & Yes & 245 & 62.5 & 331 & 63.8 & 576 & 63.2 \\
\hline & & No & 147 & 37.5 & 188 & 36.2 & 335 & 36.8 \\
\hline \multirow[t]{2}{*}{5} & \multirow[t]{2}{*}{ Are you interested in learning? } & Yes & 304 & 77.6 & 422 & 81.3 & 726 & 79.7 \\
\hline & & No & 88 & 22.4 & 97 & 18.7 & 185 & 20.3 \\
\hline \multirow[t]{5}{*}{6} & \multirow{5}{*}{\multicolumn{2}{|c|}{$\begin{array}{l}\text { Levels of Knowledge } \\
\text { 1. Nil } \\
\text { 2. Avoidance of salt, performance of regular exercise } \\
\text { 3. Weight reduction, stop alcoholism and avoid coffee } \\
\text { 4. DASH diet (dietary approach to stop hypertension) - decrease salt } \\
\text { and increase intake of foods rich in potassium, calcium and mag- } \\
\text { nesium, low fat dairy products, nuts (banana, potato, mango, green } \\
\text { leafy vegetables, whole grains) }\end{array}$}} & & & & & & \\
\hline & & & 93 & 23.7 & 127 & 24.5 & 220 & 24.1 \\
\hline & & & 104 & 26.5 & 137 & 26.4 & 241 & 26.5 \\
\hline & & & 103 & 26.3 & 106 & 20.4 & 209 & 22.9 \\
\hline & & & 92 & 23.5 & 149 & 28.7 & 241 & 26.5 \\
\hline
\end{tabular}


those who are hypersensitive and aware about nutrition in hypertension increases with increase of learning interest on hypertension at 1.0 per cent significant level.

Table 3. Correlated variables

\begin{tabular}{|l|l|l|l|}
\hline $\begin{array}{l}\text { Sl. } \\
\text { No }\end{array}$ & Correlated Variables & $\begin{array}{l}\text { Pearson } \\
\text { Correlation }\end{array}$ & $\begin{array}{l}\text { Sig. } \\
\text { (2-tailed) }\end{array}$ \\
\hline $\mathbf{1}$ & Age - Levels of knowledge & 0.112 & $0.001^{\star *}$ \\
\hline $\mathbf{2}$ & $\begin{array}{l}\text { Occupation - Levels of } \\
\text { knowledge }\end{array}$ & 0.076 & $0.022^{\star}$ \\
\hline $\mathbf{3}$ & $\begin{array}{l}\text { Are you hypertensive? - Are } \\
\text { you interested } \\
\text { in learning? }\end{array}$ & 0.091 & $0.006^{\star *}$ \\
\hline $\mathbf{4}$ & $\begin{array}{l}\text { Awareness about nutrition in } \\
\text { hypertension - } \\
\text { Are you interested in } \\
\text { learning? }\end{array}$ & 0.119 & $0.001^{\star *}$ \\
\hline $\begin{array}{l}{ }^{\star \star} \text { Correlation is significant at the 0.01 level (2-tailed) } \\
{ }^{\star C} \text { Correlation is significant at the 0.05 level (2-tailed) }\end{array}$ \\
\hline
\end{tabular}

\subsection{Correlates of Male Hypertension}

The correlates of male hypertension Table 4 shows that the variable male 'age' was having positive $(\mathrm{P}=0.168$, Sig. (2-tailed $=0.001 ; P=0.225)$, Sig. (2-tailed $=0.001)$ interaction with the variables of level of knowledge and occupation' This noticeably explains that increasing male age of the respondent with increase of their level of knowledge and occupation at 1.0 per cent significant level. In contrast the variable male 'age' is also having $(\mathrm{P}=-0.101$, Sig. (2-tailed=0.046); $\mathrm{P}=-0.128$, Sig. (2-tailed $=0.011)$ negative relationship with the variables 'Awareness about nutrition in hypertension and Are you interested in learning?' It is markedly established that the increase of male age with decrease of awareness in nutrition and learning interest and vice versa about hypertension among male

Table 4. Male related variables

\begin{tabular}{|l|l|l|l|}
\hline $\begin{array}{l}\text { Sl. } \\
\text { No }\end{array}$ & $\begin{array}{l}\text { Male Correlated } \\
\text { Variables }\end{array}$ & $\begin{array}{l}\text { Pearson } \\
\text { Correlation }\end{array}$ & $\begin{array}{l}\text { Sig. } \\
\text { (2-tailed) }\end{array}$ \\
\hline $\mathbf{1}$ & Age - Levels of knowledge & 0.168 & $0.001^{\star *}$ \\
\hline $\mathbf{2}$ & Age-Occupation & 0.225 & $0.001^{\star *}$ \\
\hline $\mathbf{3}$ & $\begin{array}{l}\text { Age-Awareness about } \\
\text { nutrition in hypertension }\end{array}$ & -0.101 & $0.046^{\star}$ \\
\hline $\mathbf{4}$ & $\begin{array}{l}\text { Age-Are you interested in } \\
\text { learning? }\end{array}$ & -0.128 & $0.011^{\star}$ \\
\hline $\mathbf{5}$ & $\begin{array}{l}\text { Occupation - Are you } \\
\text { interested in learning? }\end{array}$ & -0.119 & $0.018^{\star}$ \\
\hline
\end{tabular}

at 5.0 per cent significant level. Likewise, the variable male 'occupation' is having negative $(\mathrm{P}=-0.119$, Sig. (2-tailed $=0.018)$ liaison with the variable 'Are you interested in learning?' this is obviously confirmed that the increasing of male occupation level decrease of learning interest on hypertension and vice-versa between male at 5.0 per cent significant level.

\subsection{Correlates of Female Hypertension}

The illustrations in Table 5 demonstrate that the correlates of hypertension on female. The variable female 'age' is having positive link ( $\mathrm{P}=-0.214$, Sig. (2-tailed $=0.001)$ ) with the variable 'occupation'. This is unmistakably bear out the increases of female age with the increase of levels of occupation at 1.0 per cent significant level. In contrast, the variable female 'age' is having negative relationship ( $\mathrm{P}=-0.180$, Sig. $(2$-tailed $=0.001) ; \mathrm{P}=-0.103$, Sig. $(2$-tailed $=0.019))$ with the variables 'Are you hypertensive? and Awareness about nutrition in hypertension'.

Table 5. Female correlated variables

\begin{tabular}{|l|l|l|l|}
\hline $\begin{array}{l}\text { Sl. } \\
\text { No }\end{array}$ & $\begin{array}{l}\text { Female Correlated } \\
\text { Variables }\end{array}$ & $\begin{array}{l}\text { Pearson } \\
\text { Correlation }\end{array}$ & $\begin{array}{l}\text { Sig. } \\
\text { (2-tailed) }\end{array}$ \\
\hline $\mathbf{1}$ & Age-Occupation & 0.214 & $0.001^{* *}$ \\
\hline $\mathbf{2}$ & Age-Are you hypertensive? & -0.180 & $0.001^{* *}$ \\
\hline $\mathbf{3}$ & $\begin{array}{l}\text { Age-Awareness about } \\
\text { nutrition in hypertension }\end{array}$ & -0.103 & $0.019^{\star}$ \\
\hline $\mathbf{4}$ & $\begin{array}{l}\text { Are you hypertensive? - } \\
\text { Levels of Knowledge }\end{array}$ & 0.108 & $0.014^{*}$ \\
\hline $\mathbf{5}$ & $\begin{array}{l}\text { Awareness about nutrition } \\
\text { in hypertension- } \\
\text { Are you interested in } \\
\text { learning? }\end{array}$ & 0.184 & $0.001^{\star *}$ \\
\hline
\end{tabular}

It simply explains that the increases of female age with decrease of hypertension and aware of nutrition in hypertension among female at 1.0 per cent and 5.0 per cent significant level respectively. However, 'Are you hypersensitive with Levels of knowledge; Awareness about nutrition in hypertension with Are you interested in learning?' are the variables having positive $(\mathrm{P}=-0.108$, Sig. (2-tailed $=0.014) ; \mathrm{P}=-0.184$, Sig. (2-tailed $=0.001)$ ) relationship towards to hypertension among females at 5.0 per cent and 1.0 per cent significant level. This is clearly indicating that the increases with increase of above mentioned variables. 


\section{Discussion}

Differing studies on hypertension epidemiology in India have shown high prevalence in both urban and rural areas. Various studies have quoted an incidence varying between $4-13 \%$ of the population. In our study of a specific teacher population, it was found to be very high. ${ }^{2-4}$ Drug intake forms a major part in the control of hypertension with increasing report of the value of nutrition. ${ }^{5}$ There is an increased incidence of hypertension in males which goes along with earlier studies but females are less aware about hypertension. ${ }^{6}$ The incidence of hypertension increases with age in our results. ${ }^{7}$ As such, the knowledge of nutrition in health is found to be less even among teachers of medical school. Hence it is unwise to expect arts and science teachers to be better equipped. ${ }^{8}$ Hence in our study of college teachers we had a significantly more teachers not knowing the value of nutrition in treating hypertension even though there were sufferers of hypertension among them. Its well known as educated themselves, the keenness to know and develop knowledge was very much among teachers in our study. As there are no clear references on the awareness level of the teachers, our study seems to be the pioneering study on the topic. The main limitation of the study was a limited sample size of 911 situated in a single town. Increase in hierarchy of occupation led to decreased knowledge and decreased interest to learn which was established in our study. An awareness study on Srilankan teachers proved that there is a distinct lack of knowledge among teachers but their prevalence was a little less with $21.7 \%$ of hypertension. ${ }^{9}$ A study by Fikadu et al., showed that weight is not a factor in the high incidence of hypertension which goes against our findings. ${ }^{10}$ In another study by Agre Deepchand et al., that many factors like gender weight socioeconomic status have influenced the incidence of hypertensives. ${ }^{11}$ In these above studies, sample sizes are far less than ours with more concentration on secondary school level grades. Large multicentre trials may well show the dangerous prevalence of hypertension and a distinct lack of knowledge on various treatment modalities of the disease among college teachers.

\section{Conclusion}

This present study demonstrated that the majority of the college teachers (respondents) were aged either between
31-50 years. Around 47.4 percent of males and 36.6 percent of females were having hypertension respectively which is higher than earlier reported studies. According to the 'Suchitra's grading' nutrition scale the level of knowledge in hypertension, around half of the respondents were not aware of the role of nutrition in the management of hypertension (Grade $1 \& 2$ levels) the variable age, occupation, levels of knowledge and interested in learning about hypertension correlated with hypertension. It's clear that college teachers lack awareness about nutrition in hypertension. The teachers who suffer from the disease have better awareness. Males suffer from hypertension than females as also their knowledge. Therefore, this study suggests that there is an urgent need to improve awareness about nutrition in hypertension especially in teachers as they form the major knowledge spreader of the society.

\section{References}

1. Kearney P, Whelton M, Reynolds K, Muntner P, Whelton PK, He J. Global burden of hypertension: Analysis of worldwide data. Lancet. 2005; 365:217-23. crossref

2. Gupta PC, Gupta R, Pendnekar MS. Hypertension prevalence and blood pressure trends in 88653 subjects in Mumbai India. Journal of Hum Hypertens. 2004; 18:853-6. crossref PMid:15306829

3. GuptaR,SharmaAK.Prevalenceofhypertensionandsubtypes in an Indian rural population. Clinical and electrocardiographic correlates. Journal of Hum Hypertens. 1994;8:823-9. PMid:7853325

4. Gilberts EC, Arnold MJ, Grobbee DE. Hypertension and determinants of blood pressure with special reference to socioeconomic status in a rural South Indian community. Journal of Epidemiol Commun Health. 1994; 48:258-61. crossref

5. Lawrence JA, Michael WB, Stephen RD, Njeri K, Patricia JE, Frank MS. Dietary approaches to prevent and treat hypertension. Hypertension. 2006; 47:296-308.

6. Everett, Bethany, Anna Z. Gender differences in hypertension and hypertension awareness among young adults. Biodemography and Social Biology. 2015; (61.1):1-17.

7. Lacruz ME, Kluttig A, Hartwig S, et al. Prevalence and incidence of hypertension in the general adult population: results of the CARLA-cohort study. Schillaci. G, ed. Medicine. 2015; 94(22):e952.

8. Torti FM, Adams KM, Edwards LJ, Lindell KC, Zeisel SH. Survey of nutrition education in US. Medical schools - an instructor-based analysis. Med Educ Online. 2001; 6:8. crossref PMid:28253745 
9. Wijayathunge UPK, Hettiaratchi UPK. Assessment of knowledge and risk factors of hypertension among school teachers in a selected district in North Central Province of Sri Lanka. International Journal of Scientific and Research Publications. 2017; 7(11):404-8.

10. Fikadu G, Lemma S. Socioeconomic status and hypertension among teachers and bankers in Addis Ababa,
Ethiopia. International Journal of Hypertension. 2016; 4143962:1-7.crossref PMid:27313874 PMCid: PMC4893435

11. Agre DH, Katti SM, Mubashir A, Mallapur. Prevalence of hypertension and its associated risk factors among secondary school teachers of Belagavi city. Indian Journal of Preventive Medicine. 2015; 2(3):45-8. 